\title{
O ALOJ AMENTO DE MÃES DE RECÉM-NASCIDOS PREMATUROS: UMA CONTRIBUIÇÃO PARA A AÇÃO DA ENFERMAGEM
}

\author{
The accommodation for mothers of preterm newborns: a \\ contribution to the Nursing action.
}

\section{Alojamiento para madres de recién nacidos prematuros: un aporte a la acción de la enfermería.}

\begin{abstract}
RESUMO
0 estudo teve o objetivo de apreender o "motivo porquê" de a mãe permanecer na unidade hospitalar durante a internação do filho prematuro na Unidade de Terapia Intensiva Neonatal. Foi realizado com 12 mães de recém-nascidos prematuros, em um hospital maternidade municipal do Rio de Janeiro, em 2007. Adotou-se como suporte metodológico a Fenomenologia Sociológica de Alfred Schutz. A Entrevista Fenomenológica foi a técnica utilizada para captar o contexto vivencial das mães na unidade hospitalar, compreendendo que a sua permanência está ligada à ação de cumprir seu papel de ser mãe. A vivência das mulheres é retratada como um processo difícil, triste e conflituoso. Concluímos que as mães atualmente estão presentes, mas não estão inseridas nesta realidade intensiva. Dessa forma, entendemos que é necessário mudar esse paradigma intensivista incorporando o cuidado humanizado, inserindo a mãe e sua família no ambiente neonatal.
\end{abstract}

Palavras-chave: Mães. Alojamento. Enfermagem Neonatal. Neonatologia. Prematuro.

\begin{abstract}
The study aimed to understand 'why' the mother remains in hospital during the hospitalization of the premature child in the Neonatal Intensive Care Unit. This was conducted with twelve mothers of premature infants in a municipal maternity hospital in Rio de Janeiro in 2007. We have adopted as a methodological support the Alfred Schütz's sociological phenomenology. The phenomenological interview was the technique used to capture the context of mothers living in the hospital, understanding that their stay is linked to their role of being a mother. The life experience of these women is reported as difficult, sad and full of conflicts. We concluded that the mother presence is more frequent, but are not included in this intensive reality. Thus, we believe it is necessary to change this paradigm incorporating a humanized care by inserting the mother and her family in the neonatal environment.
\end{abstract}

Keywords: Mothers. Accommodation. Neonatal Nursing. Neonatology. Premature.

\section{Resumen}

El presente estudio tuvo como objetivo comprender la razón por la cual la madre permanece en el hospital durante la hospitalización del bebé prematuro en la unidad de cuidados intensivos neonatal. La investigación se realizó con un grupo de 12 madres de recién nacidos prematuros en un hospital municipal de maternidad en Río de Janeiro en el aòo de 2007. Como base metodológica se utilizó la sociología fenomenológica de Alfred Schutz. La técnica de la entrevista fenomenológica fue aplicada para captar el contexto de vida de las madres durante su estancia en el hospital. Esto nos permitió entender que su presencia está ligada a la acción de cumplir con su papel de madre. La experiencia de estas mujeres se presenta como un proceso difícil, triste y polémico. Llegamos a la conclusión de que a pesar de que estas madres están presentes, no están siendo incluidas en esta realidad intensiva. Por lo tanto, creemos que es necesario cambiar este paradigma de la incorporación de cuidados intensivos humanizados mediante la inserción de la madre y su familia en el ambiente de los cuidados neonatales.

Palabras clave: Madres. Alojamiento. Enfermería neonatal. Neonatología. Prematuro.

\footnotetext{
${ }^{1}$ Mestre pelo Programa de Pós-Graduação em Enfermagem da Universidade do Estado do Rio de Janeiro. Especialista em Enfermagem Pediátrica pela Universidade Federal do Rio de Janeiro. Enfermeira da Unidade de Terapia Intensiva Neonatal do Hospital Municipal Oswaldo Nazareth/Praça XV da Secretaria Municipal de Saúde e defesa Civil do Rio de Janeiro. Brasil. E-mail: bbertolossi@gmail.com ${ }_{\perp}^{2}$ Doutora em Enfermagem. Bacharel em Filosofia. Especialista em Ética aplicada e Bioética. Professora Titular da Faculdade de Enfermagem da UERJ, integrante do Programa de Mestrado FENF/UERJ. Brasil. Email: benedeusdara@pq.cnpq.br/benedeusdara@gmail.com
} 


\section{INTRODUÇÃO}

Atualmente, a sobrevivência dos bebês prematuros tem sido uma realidade constante em nosso cotidiano. Porém, a qualidade de vida desses seres imaturos é ainda um desafio que buscamos, dia a dia. A incorporação desse ser na sociedade, até há pouco tempo considerado inviável, passa por uma série de fatores intimamente relacionados com a saúde mental, social e familiar. ${ }^{1}$

Apesar dos avanços no conhecimento do neonato e na tecnologia de ponta oferecida na assistência, o ambiente da Unidade de Tratamento Intensivo Neonatal (UTIN), voltado basicamente para a salvação e recuperação clínica, apresenta um grande contraste em relação à vida uterina. A UTIN configurase em um ambiente de estímulos excessivos, apresentando luz forte e constante, intenso ruído, múltiplos procedimentos e manuseio frequente, nem sempre fornecendo oportunidades para manutenção do conforto do recém-nascido. ${ }^{1}$

0 momento do manuseio é determinado pela rotina da UTIN, e os procedimentos são realizados de forma mecânica e técnica, não respeitando, muitas vezes, as necessidades de conforto, sono e repouso deste ser em processo de crescimento e desenvolvimento. Além da rotina intensiva de cuidado a este pequenino ser, ainda se privilegia a tecnologia em detrimento do cuidado humanizado, e a privação de cuidados parentais é notória neste ambiente.

Embora as estratégias para a introdução da família no contexto neonatal tenham sido evidenciadas desde a década de 90 do século passado, garantidas no artigo 12 do Estatuto da Criança e do Adolescente (ECA)-Lei $n^{0} 8.069 / 90$ e apoiadas pelo Ministério da Saúde, a presença materna na UTIN nem sempre é uma realidade bem aceita pelos profissionais que lá atuam. $^{2}$

A mãe, na maioria das vezes, passa a ser mera expectadora dos cuidados especializados prestados pela equipe de saúde, tendo como pano de fundo um cenário composto de aparelhos, fios, estimulação sonora incessante e os profissionais da equipe de saúde executando procedimentos invasivos. A contemplação materna desta rotina aterrorizadora somada à precisão do cuidado das enfermeiras com seu filho traduzem a dimensão de sua incapacidade de auxiliá-lo. É comum a mãe se sentir culpada por não saber cuidar de seu próprio filho, vendo a enfermeira como a mãe perfeita e ideal. ${ }^{3}$

No bojo das discussões sobre a presença parental junto ao filho, em 1995, foi criado o alojamento de mães na instituição estudada, permitindo que as mães, por ocasião da alta, pudessem ali permanecer para acompanhar, em período integral, seus filhos internados na UTIN. Mesmo com tantos anos de funcionamento, ainda não há dispositivo legal que autorize a implantação desse tipo de alojamento nas unidades hospitalares, o qual tem sido criado por uma decisão institucional a partir das políticas públicas como o ECA e a Iniciativa Hospital Amigo da Criança. Desse modo, esta assistência às mães tem sido implementada de forma diversificada em muitas unidades hospitalares, pois algumas abrigam mães de bebês internados e outras possibilitam a permanência apenas das mães que amamentam, daí serem nomeadas "alojamentos de mães nutrizes".

Neste ambiente, no qual se experiencia com frequência risco de morte iminente, pouco se faz para estimular o vínculo entre a mãe e este ser tão frágil.

A partir desse contexto, o estudo teve o objetivo de apreender o "motivo porquê" de a mãe permanecer na unidade hospitalar durante a internação do filho prematuro na UTIN.

Este estudo pretende fornecer subsídios para 0 desenvolvimento da ação acadêmica e profissional mais próxima da realidade materna, reforçando a valiosa contribuição da mãe junto à criança, que vivencia os momentos críticos da internação hospitalar.

Ao buscar trabalhos publicados nesta temática, na Biblioteca Virtual em Saúde, compreendendo as revistas disponíveis nas bases de dados LILACS, MEDLINE e BDENF e com a utilização dos descritores: UTIN, neonatal, mãe, mãefilho e prematuro, encontramos ricas informações. A produção científica representada por 14 estudos no LILACS, 157 no MEDLINE e 9 na BDENF aborda questões relacionadas aos sentimentos e emoções dos pais e da família durante a internação do filho, à percepção dos pais diante da internação e aos cuidados prestados pela equipe.

No entanto, observamos a limitada publicação de estudos voltados à investigação do vivido das mães que acompanham seus filhos em UTIN e mesmo assim tratavam da amamentação. Assim, este estudo poderá minimizar a lacuna do conhecimento existente na área e, dessa forma, desvelar a possibilidade de uma assistência de enfermagem mais sensível às necessidades maternas.

\section{REVISÃO DE LITERATURA}

\section{Mães e 0 bebê prematuro na Unidade de Tratamento Intensivo Neonatal}

0 nascimento de um bebê antes do termo caracteriza um momento de crise para a família. Diante do risco de morte da criança, é comum os pais desencadearem uma série de sentimentos de culpa, ansiedade, preocupação e confusão. Este fato é somado ao não desenvolvimento do contato mãe-bebê e amamentação precocemente. ${ }^{3}$ 
As mães que vivenciam o processo de prematuridade do filho podem reagir de diferentes formas à situação de tensão. Em algumas situações, elas parecem se entregar totalmente ao bebê, mantendo um intenso envolvimento. Porém, a maioria das mães desenvolve medo, insegurança e rejeição por aquele ser tão pequeno e frágil, tão diferente daquele desejado. A habilidade com que as enfermeiras prestam assistência ao prematuro faz a mãe se sentir incapaz de cuidá-lo e apenas confiar nos cuidados especializados da equipe. 0 futuro desta criança fora do ambiente neonatal dificilmente é imaginada pelos pais. ${ }^{4,5}$

Os pais, além de desenvolverem a perda do bebê perfeito que imaginavam, também lamentam as deficiências do filho que produziram, desenvolvendo sentimentos de culpa e impotência, consciente e inconscientemente. Neste pensar, faz-se necessário o apoio da equipe de enfermagem no sentido de facilitar o processo de adequação da imagem do bebê imaginário com a imagem do bebê real, facilitando, assim, 0 processo de luto do bebê imaginário e enfrentamento das diferenças do bebê real. ${ }^{1,6}$

Antes de terem confiança em si mesmos como seres capazes de se relacionar com o bebê prematuro, os pais desenvolvem cinco estágios importantes no processo de ligação ao filho. 0 primeiro estágio corresponde ao relacionamento tênue, através das informações clínicas em relação à situação do filho, transmitidas pelos profissionais de saúde. Em seguida observam atentamente os movimentos apresentados pelo bebê quando é manipulado pela equipe. No terceiro estágio, os pais tentam identificá-lo como uma pessoa, apreciam os movimentos e os reflexos apresentados pela criança, porém não ousam estimulá-los. No estágio seguinte, tentam produzir uma reação no filho, correspondendo ao início da visão de si mesmos como pais desta criança. Assim, podem ver-se como responsáveis por suas respostas. No último estágio, os pais ousam pegá-lo e segurá-lo, balançá-lo e alimentá-lo. A ligação afetiva entre eles já está formada, e os pais passam a acreditar que podem confortá-lo e tratá-lo. Esta fase mostra que os pais estão prontos para levarem este filho para casa. ${ }^{7}$

No entanto, para transcorrer esses cinco estágios, fazse necessário o apoio da equipe aos pais, principalmente à mãe, no reconhecimento de seu filho prematuro como um ser que necessita dela para seu desenvolvimento.

Portanto, devemos proporcionar à mãe o conhecimento da real situação de seu filho, de acordo com suas reais necessidades. É importante, também, estimularmos o cuidado materno assim que a criança se estabilize, a fim de que a mãe desenvolva sentimentos de segurança e confiança para cuidar deste ser tão diferente.

\section{METODOLOGIA}

Este estudo foi apoiado na abordagem qualitativa, uma vez que responde a questões particulares e preocupa-se com uma realidade suscetível a captar motivos, aspirações, atitudes, que não são questões quantificáveis.

Na busca de apreender a essência do fenômeno, ao se voltar para as coisas mesmas e para o mundo vivido, acabamos "por negar sujeito e mundo como independente um do outro" (8:844). "O objeto do conhecimento não é nem o sujeito, nem o mundo, mas o mundo enquanto vivido pelo sujeito". Evidenciase, assim, a intencionalidade da consciência(8:844).

Assim, por meio da abordagem fenomenológica, buscamos captar o "motivo porquê" de a mãe permanecer na unidade hospitalar durante a internação do filho prematuro na UTIN. 0 relato dessas mulheres, a partir de suas experiências vividas junto ao filho prematuro, pode nos auxiliar na melhor maneira de adequar a assistência durante este período.

Desse modo, Capalbo nos chama a atenção sobre as ideias de Husserl quando destaca que "a fenomenologia é uma ciência rigorosa, mas não exata, uma ciência eidética que procede por descrição e não por dedução. Os seus fenômenos são os vividos da consciência, os atos e os correlatos dessa consciência 9:18".

A descrição do vivido das mães diante dos desafios que se apresentam cotidianamente, pelo estado de saúde de seus filhos, alternando momentos de melhora e de piora do estado geral, além do distanciamento da família, precisa ser explicitada como um fenômeno a ser apreendido.

Nesse sentido, o estudo foi realizado com base na fenomenologia visto que atua no real vivido, buscando compreender o que somos e o que fazemos, de forma individual e coletiva. ${ }^{10}$

Neste pensar, o mundo da vida, também conhecido como o mundo do senso comum, é a forma de descrever o mundo intersubjetivo experienciado pelo homem. Nele, cada indivíduo possui uma formação singular, construída através da experiência das relaç̃oes vividas, que possibilita assumir um espaço único na sociedade, permitindo a aquisição e sedimentação de conhecimentos e experiências genuínas durante sua trajetória existencial. ${ }^{10}$

Assim, é impossível dois indivíduos ocuparem o mesmo lugar na sociedade, pois cada um tem sua situação biográfica diferente e singular. Tal singularidade vai influenciar a forma como cada pessoa ocupará o espaço da ação social, decorrência da bagagem de conhecimentos adquiridos e experiências vivenciadas previamente, que caracterizam as tipificações do mundo da vida. ${ }^{11}$ 
0 objetivo fundamental na fenomenologia sociológica baseia-se na compreensão e interpretação da ação social. Esta é definida como sendo "vivências conscientes intencionalmente relacionadas com o outro", "emergindo espontaneamente, com um caráter previamente projetado" 12:134. Portanto, esta ação corresponde à ação projetada por um ator social, dotada de significados subjetivos, ou seja, de intencionalidade, e que podem ser dirigidos para o passado, presente ou futuro.

Os "motivos porquê" estão presentes nas realizações passadas, ou seja, nas realizações e fatos já concluídos, podendo, contudo, influenciar nas ações presentes, pois não são esquecidos. ${ }^{13}$

Nesse sentido, tivemos acesso ao cotidiano da ação social das mães, ao permanecerem na unidade hospitalar, durante a internação de seus filhos prematuros na UTIN, através das suas próprias falas a partir das quais pudemos captar 0 "motivo porquê"desta ação.

\section{Cenário do estudo}

0 estudo foi realizado no Alojamento de Mães de um Hospital-Maternidade Municipal de médio porte, situado na cidade do Rio de Janeiro, que oferece atendimento de emergência 24 horas para mães em trabalho de parto, tendo seu perfil direcionado para o atendimento de gestantes de alto risco.

A maternidade possui o título de Hospital Amigo da Criança desde 1998 e admite bebês de risco de demanda interna ou externa. É composta de oito leitos de UTIN e quinze de unidade intermediária, e seis leitos de enfermaria canguru, além do banco de leite, alojamento conjunto, ambulatório de pré-natal, ambulatório de follow up, ou recriar, e sala de vacinas.

As visitas dos pais são permitidas em horário ampliado, das 8 às 21 horas, sendo que as mães internadas podem visitar seu filho a qualquer momento. As mães que estiverem de alta $\mathrm{e}$ optarem por permanecer na maternidade até a alta de seu filho poderão ficar no alojamento de mães, sendo permitida a visita a seus respectivos bebês no complexo neonatal em horário integral. A rotina deste setor permite a visita de avós, irmãos, tios do recém-nascido e amigos da família, em dias úteis, das 14 às 15 horas, os quais recebem o acompanhamento de uma equipe de assistentes sociais e psicólogos.

A escolha desse hospital-maternidade como cenário de pesquisa se justifica por sua estratégia de Alojamento de Mães implantada, permitindo-nos investigar esse vivido da permanência das mães junto a seus bebês prematuros internados na UTIN.

Os sujeitos do estudo foram 12 mães de recém-nascidos prematuros que permaneceram no Alojamento de Mães durante a internação do filho na UTI neonatal. Ao buscar o "motivo porquê" da ação maternal nessas condições, utilizamos a entrevista fenomenológica.

A realização deste estudo foi precedida pelo encaminhamento do seu projeto ao Comitê de Ética e Pesquisa da Secretaria Municipal de Saúde do Rio de Janeiro, tendo sido obtido parecer favorável com o n² 22A/2007.

Inicialmente buscamos informaç̧ões sobre a situação clínica de seus filhos nos prontuários a fim de familiarizar-nos com a realidade delas. Nesta leitura, verificamos quais recémnascidos eram prematuros, para assim identificar os sujeitos do estudo. Em seguida, tentamos estabelecer uma relação empática com as mães de bebês prematuros que permaneciam na unidade hospitalar, durante os momentos em que se encontravam com seus filhos.

As falas foram captadas por meio da entrevista fenomenológica com as mães, após a obtenção da assinatura do Termo de Consentimento Livre e Esclarecido de cada participante do estudo. Tal documento respeita os aspectos preconizados pela Resolução n 196/96 do Conselho Nacional de Saúde, tendo sido assegurados a privacidade e 0 anonimato das entrevistadas através da designação de codinomes.

Cabe ressaltar que a entrevista fenomenológica se mostra desprovida de preconceitos, hipóteses e pré-julgamentos, sendo a pergunta utilizada fruto da teoria que norteia a investigação do autor. ${ }^{10}$ Para a realização da entrevista, utilizamos a seguinte questão orientadora:

Como tem sido a sua vida após a decisão de estar no alojamento de mães para acompanhar seu filho internado na UTIN?

Por tratar-se de pesquisa com abordagem qualitativa, seus resultados não devem ser generalizados, representando uma das limitações do estudo.

\section{RESULTADO E DISCUSSÃO}

A análise teve como base a apreensão do "motivo porquê". Este refere-se ao passado e surge a partir dos contextos vivenciados por mães durante a hospitalização dos filhos na UTIN, evidenciados nos atos já concluídos, explicitando aspectos da realização do projeto; portanto, eles têm uma realização temporal voltada para o passado. A captação do "motivo porquê"é possível na medida que o ator social se volta para o seu passado, observando seus próprios atos. ${ }^{13}$

Portanto, esta ação social é dotada de significados subjetivos, cuja intencionalidade pode ser dirigida para o passado, presente ou futuro. Dessa forma, os "motivos porquê" têm suas raízes nas realizações passadas, ou seja, nos fatos já concluídos, podendo, contudo, influenciar as ações presentes, pois não são esquecidos. ${ }^{13}$ 
Nesse sentido, tivemos acesso ao contexto vivencial, que corresponde ao "motivo porquê" e possibilita a compreensão do significado da existência de cada mãe cuja situação biográfica a direciona para agir de tal ou qual forma.

Por meio da análise das entrevistas pudemos compreender que o cotidiano da ação social de permanecer na unidade hospitalar acompanhando o filho está ligado ao cumprimento do seu papel de ser mãe, socialmente construído e inserido em seus mundos vida. Dessa forma, a presença materna nos cuidados ao filho é uma possibilidade de se sentir segura, mostrando que o ato de cuidar, antecipadamente, faz reconhecer o bebê como seu filho, e o bebê a identificá-la como mãe capaz de lidar com ele, ser tão pequenino.

[...] fazendo nosso papel de mãe... sempre que a gente pode a gente está lá pra dar um carinho, pra dar uma força, ajudar... (Saudade)

[...] eu fico lá esse tempo, o tempo que for necessário até ele poder ir pra casa... você fica porque você tem que ficar mesmo... eu quero ficar por causa do filho [...]. (Ternura)

Não tem mãe que queira largar seu filho na UTI pra ir pra casa, então ébom ter mesmo um alojamento de mães dentro do hospital. (Solidariedade)

Pelo meu filho eu faço tudo, ficaria em qualquer lugar, onde ele estivesse... enquanto ele não sair daqui, eu não vou embora [...]. (Dor)

A possibilidade de cuidado ao bebê prematuro, pela mãe, é um hábito pouco frequente nas Unidades de Tratamento Intensivo Neonatal, sendo muito desejado por elas durante a internação do filho. Muitas mulheres passam meses sonhando com este momento, fato nem sempre valorizado pelo profissional de saúde.

[...] pela segunda vez eu peguei meu neném no colo... pedir, não peço, porque não seise posso tocar ou não. Aíhoje, ele veio, pegou, botou ela no meu colo, quer dizer, o maior carinho com a gente. (Felicidade)

É importante, no entanto, orientar as mães quanto à maneira e ao momento ideal de tocar seus bebês, favorecendo vivências positivas ao promover esses contatos durante a hospitalização. Os estímulos positivos podem contribuir fortemente para a evolução clínica dessas crianças, principalmente se esses toques forem de suas próprias mães.
Esses toques ainda possibilitam que as mães conheçam mais os aspectos individuais de seus filhos, diferenciando suas ações dos demais profissionais. ${ }^{14-16}$

0 cuidado por meio do toque é associado ao sentido de dar conforto, sendo, também, expressado como exploração do corpo desse bebê pequenino. Nesse sentido, compreendemos que o cuidar, para essas mães, é mais que uma ação, é um ato de reconhecimento de seu próprio filho e, também, de seu papel de mãe. ${ }^{14-16}$

0 fato do hospital estudado ser Amigo da Criança direciona os cuidados para o incentivo à amamentação. No entanto, podemos ver que em algumas situações a mãe é considerada apenas uma nutriz, não sendo estimulado o contato e o cuidado materno.

Eu pego ele, mas somente pra amamentar, só pego pra amamentar e boto ele lá dentro de novo. (Ternura)

No contexto da unidade intensiva, algumas mães até perdem o interesse em cuidar, pois visualizam seu bebê como inacabado, e elas como incapazes de cuidar. Para estas mães, o cuidado é algo que só irá acontecer no futuro. 0 cuidar é mais que uma ação, é um ato de reconhecimento de seu próprio filho, e também de seu papel de mãe.

O cuidar só vai acontecer quando eu for pra minha casa... eu vou cuidar de tudo... dar um banho, botar as roupinhas. Até hoje não pude botar roupinha porque ele estava na incubadora, ver as coisinhas dele... ver ele no berço dele... dar mais carinho, mais atenção... que acho que fica um pouco limitado também ... é aproximar mais da criança... conhecer mais a criança... somos mãe e filho, mas ainda estamos nos conhecendo. (Ternura)

A permanência materna no alojamento de mães está relacionada também ao medo de deixar o filho sozinho, pois elas veem a equipe, apenas, como executora de tarefas para a manutenção da vida, sem a possibilidade de confor to de seu bebê. Ou seja, as próprias mães observam o desenvolvimento da assistência mecanicista e biologicista presente nas unidades de alto risco, em detrimento da ação materna diferenciada.

[...] porque, bem ou mal, o outro já tem seis anos e está com meu pai e minha mãe; estão ajudando, e o daqui ficaria sozinho, mas com a equipe de enfermagem e tudo, mas eles estão ali pra poder, pra furar, pra mexer, não tem ninguém pra dar o carinho, fazer um carinho nele [...]. (Amor) 
A vivência das mulheres no alojamento de mães é retratada nas falas de quase todas elas como um processo difícil, triste, pois, ao mesmo tempo que sofrem pela criança internada, também se sentem isoladas do mundo, longe das pessoas que mais gostam.

\section{[...] tem sido um pouco triste também porque a gente fica longe da nossa família..., a gente sente saudade, sente falta da mãe, do pai assim, dos familiares. É muito triste a gente fica um pouco isolado neste ambiente; o que consola a gente éa gente estar perto do nosso filho, da nossa nova familia. (Saudade)}

[...] a gente já vive vinte quatro horas chorando, vinte e quatro horas chorando [...]. (Felicidade)

Tem sido difícil... ela estar lá dentro da incubadora ... dá uma tensão, dou uma chorada, mas está sendo normal. A tristeza depois para... levo a vida normal, aí o dia passa e eu estou com meu filho, a gente vai levando... (Solidão)

A vivência é difícil ... graças a Deus já está bem melhor. Já saiu do tubo, mas está aqui no hospital. (Esperança)

0 desamparo dessas mães é quase total, pois não há nenhum familiar próximo, além da criança, para consolá-las. Desse modo, promovem o conforto uma às outras, tornandose uma grande família.

[...] tipo uma segunda família mesmo, porque a gente tem de ficar lá no hospital todo dia e tem que conviver bem com as pessoas. (Saudade)

Bom, a gente ali, somos oito, nós criamos uma familia. Eu sou a mais velha de todas elas... Aíeu falo para ela - vocês são minhas filhas [...]. (Felicidade)

\section{[...] é tipo uma segunda familia mesmo, porque a gente tem que conviver bem com as pessoas ... tem que aprender... tem pessoas que a gente nunca viu na vida, que de uma hora para outra começam a ter parte de seu cotidiano. (Saudade)}

0 conflito com o inesperado, novo e pequenino bebê, é um grande desafio para estas mulheres. A rotina aterrorizante desta unidade, com procedimentos dolorosos, invasivos e constantes, faz com que se sintam impotentes e amedrontadas nessa nova realidade. A gravidade dos outros bebês e a possibilidade iminente de morte de seu filho é a causa do medo contínuo.

[...] a situação é grave... o meu também está lá, podia ser com ele... (emocionada)... fica complicado... é muito difícil ficar aqui... outro dia eu tava lá, meu filho tava na incubadora, aí eu escutei, tinha uma mãe sentada chorando, e a pediatra dizia mãezinha tenta ficar calma, mãezinha, ele era muito pequenininho... quer dizer, houve um óbito. Daí eu em pé perto da incubadora do meu filho, que é pequenininho, mede trinta e sete centímetros... eu escutei ela falar isso - mãezinha ele era muito pequeno, foi... nossa, foi horrível ... dá medo [...]. (Amor)

0 alojamento é visto como uma excelente iniciativa de valorização das mães, sendo uma possibilidade única poderem estar com seus filhos. Ressaltam, ainda, que é uma iniciativa inovadora, pois muitos hospitais não possuem este modelo de assistência.

[...] para a gente é só um refúgio... A gente espera o bebê ficar aqui o tempo que for preciso... se isolar a gente num lugar, se pode cair numa depressão. (Felicidade)

[...] se eu tivesse que ir e vir todo dia eu gastaria uns sete reais eu nunca vi isso em hospital nenhum, eu tive minha filha no Bonsucesso, é a primeira vez que eu vejo isso em um hospital, eé muito bom ter isso mesmo. (Solidariedade)

Eu achei que é um lugar bom pra ficar ali... Os outros hospitais não têm isso, tem que ir pra casa pra depois voltar pra ficar com seu filho... [...]. (Solidão)

Tem alguns hospitais que não dão a oportunidade de a gente ficar perto do nosso filho... de a gente poder estar ali, praticamente vinte quatro horas com ele [...]. (Dor)

0 alojamento passa a ser um local de aprendizagem, de trocas de experiências, fazendo com que cada uma respeite o espaço da outra, tendo respeito, amizade e, sobretudo, aprender a conviver socialmente. 
[...] A gente tem que aprender... tem pessoas que a gente nunca viu na vida, que de uma hora pra outra começam a ter parte de seu cotidiano, tem que ter dedos... tem que está dialogando... trocando ideias... aprender a conviver [...]. (Saudade)

[...] tem sido dificil, mas aqui a gente aprende a ser mais humana, aprende a gostar das pessoas por mais defeito que elas tenham, e a ser amiga. (Tristeza)

Os relatos das mães retratam a situação que vivem durante a internação do filho no alojamento de mães, mostrando-se difícil e solitária a permanência no hospital. A mulher torna-se dividida, pois, ao mesmo tempo que é mãe e possui o seu filho internado na UTIN, também se preocupa com o restante da família que deixou em casa. Muitas falam da tristeza de deixar o outro filho com familiares, tanto tempo sem ver; outras lamentam deixar o marido, a mãe, os pais.

Em um estudo realizado com mães acompanhantes de bebês prematuros, foi observado que este sentimento de ambivalência e conflito de papéis faz parte do cotidiano dessas mulheres durante a internação do filho. Esta situação deflagra sentimentos de impotência diante de tantas funções, mostrandoas divididas, pressionadas e sobrecarregadas. ${ }^{17}$

[...] E a gente fica muito dividida..., às vezes você acorda de madrugada com uma chorando, com saudade de casa, dividida porque deixou seu filho em casa, que não devia ter deixado seu filho em casa. (Felicidade)

[...] mas é difíicil, é meio complicado porque você se abala, você se estressa, você quer ir pra casa, você não sabe. Às vezes não aceita ficar, às vezes acha que já ficou tempo demais, não aguenta mais ficar e de repente você pensa no seu filho.... Muito difícil ficar longe de casa, da família, [...] é muito complicado... (Ternura)

0 desespero e a dor resumem a vida dessas mulheres, que são visita para o filho, mas não podem receber visitas. Somente podem receber seus maridos na recepção, durante 0 horário de visitas permitida para o bebê, e isso faz com que se sintam só e desamparadas.

[...] se a gente pudesse receber visitas ... como todas aqui recebem ... ter um horário pra receber visitas lá, só que não pode...é praticamente um quarto, um alojamento, não pode e a gente recebe visitas nos corredores, recebe visitas aqui dentro do neonatal...acho que deveria ter um cantinho para as mães que ficam no alojamento receber suas visitas [...]. (Desconfiança)

Observamos, por meio das convergências das falas, que a vivência materna no alojamento de mães é cansativa e desgastante para a mulher, ocorrendo muitas demandas e pouco lazer e descanso. Muitas referem a rotina cansativa de ter de, de três em três horas, tirar leite, de ficar na UTI com o filho, restando pouco tempo para se refazerem do cansaço. Outro fato relatado é a falta de lazer, ou atividade para ocupar a mente, que possibilitaria uma fuga da realidade por um certo período, evitando assim o estresse e a exaustão.

[...] venho pra UTI, vou ver meu neném, dou banho, troco...tiro leite... converso com as meninas e volto pro alojamento... não tem nenhuma atividade pra ocupar a mente... minha ocupação é ir toda hora lá ver se meu filho está mijado, se está acordado... éa única coisa para fazer [...]. (Solidariedade)

[...] de três em três horas você tem que ficar tirando leite, você tem que estar amamentando, então eu só paro lá mesmo alguns momentos pra cochilar, pra descansar mesmo, e é curto o tempo... nem dá pra dormir... descansar pouquíssimo... por causa da amamentação, tirar o leite, que é no período de 3 em 3 horas, e édireto. (Ternura)

[...] aprender certas coisas lá dentro, aprender uma união, a dividir as coisas, dividir as dores e ser unidos... amizade... perseverança, porque é uma luta, é uma caminhada longa. Hoje está bem, amanhã não está... eles vão se recuperando aos pouquinhos. É um ambiente pesado, a gente tenta contornar fazendo alguma coisa. Tem privação de grandes coisas... uma televisão pra distrair um pouco a cabeça... temos que manter tudo organizado, manter limpo. (Desconfiança)

Tem hora que você se sente presa, tem hora que você sabe que não está presa, que você pode sair, mas seu filho vai ficar. É uma coisa muito esquisita [...]. (Solidariedade) 
Apesar de afirmarem que o alojamento de mães não é uma prisão, percebemos que elas se contradizem ao julgar o cenário pouco familiar com privação de atividades de lazer, bem como da necessidade de uma higiene mental. A liberdade narrada pelas mães se trata apenas da saída daquele ambiente pesado, mas não podem fugir da realidade de serem mães de prematuros, da dificuldade da separação, da impossibilidade de levar seus filhos para casa. Isto, ao nosso ver, configura uma prisão na própria realidade da vida dessas mães.

Através da convergência das falas, pode-se compreender que a figura da mulher não existe nesse ambiente intensivo. No momento em que ela tem alta e decide permanecer como acompanhante do filho prematuro, passa a ser considerada apenas uma mãe nutriz, em detrimento de seus direitos de mulher cidadã. Da mesma forma, elas também não se reconhecem como mulheres-mães e se convencem do seu árduo papel sofredor, de total doação e sofrimento como natural do papel materno.

\section{CONSIDERAÇÕES FINAIS}

Ao longo de nossa trajetória de vida profissional, como docentes e enfermeiras pudemos experienciar o convívio com recém-nascidos prematuros e suas mães durante a internação na UTIN. Nesta realidade de cuidados intensivos, em que 0 bebê se encontra em risco de morte iminente, preocupava-nos o fato de este ser tão pequenino e dependente não poder receber o conforto e carinho maternos adequados. A separação entre mãe e filho, deflagrada no momento do parto, demarcava o início de uma longa caminhada de sofrimento e submissão aos cuidados da equipe.

A rotina barulhenta e repleta de surpresas da UTIN não permite espaço para a mãe, com seu sofrimento, incerteza e dúvidas. Nela, um bebê prematuro pode passar meses internado, tendo a mãe o direito de permanecer em uma área física próxima à UTIN, denominada Alojamento de Mães. Em contrapartida, aquelas que permaneciam na unidade hospitalar muitas vezes não tinham uma participação ativa durante a internação do filho, ficando claro a falta de uma estrutura que viabilizasse a presença materna neste ambiente tecnológico.

Dessa forma, o presente estudo revelou que o vivido das mães na unidade hospitalar expressa a ação social de serem mães, esquecendo o lado mulher, e reforçando a necessidade de se doarem integralmente ao filho internado, mesmo estando dividida entre ele e sua família.

As ações de incentivo à participação materna na recuperação do filho estão direcionadas ao ato biológico de amamentar, mostrando que, muitas vezes, os profissionais associam a visita da mãe à ação funcionalista de atender ao objetivo institucional da amamentação. Ou seja, permitem que as mães visitem os filhos, mas não estimulam sua participação nos cuidados; permitem a amamentação, mas não ampliam o olhar de humanização e acolhimento subjacente a esta iniciativa.

O Alojamento de Mães é expresso como uma iniciativa excelente e inovadora, possibilitando a permanência das mães acompanhantes na unidade hospitalar. Elas compreendem a sua importância no desenvolvimento do filho e não admitem a possibilidade de sair da unidade hospitalar sem o bebê saudável em seus braços. Assim, ele é descrito como um espaço de convivências, onde as mães se apoiam, trocam experiências e acolhem as dores e angústias mutuamente. Esta aproximação gera uma cumplicidade e amizade, fazendo-as considerar o grupo de mães como uma segunda família.

Concluímos que as mães deste estudo, atualmente, estão presentes na UTIN, mas não são presenças plenas nesta realidade intensiva. Dessa maneira, entendemos que é necessário mudar esse paradigma intensivista e pensar nos benefícios do cuidado humanizado, incluindo a mãe e, na medida do possível, a família no ambiente da UTIN. É preciso possibilitar o estreitamento dos laços afetivos e a confiança materna perante este ser tão diferente, em momento crítico, tornando essa vivência menos sofrida.

\section{REFERÊNCIAS}

1-Araújo BBM. Vivenciando a internação do filho prematuro na UTIN: (re)conhecendo as perspectivas maternas diante das demandas neonatais [dissertação de mestrado]. Rio de Janeiro (RJ): Faculdade de Enfermagem/ UERJ; 2007.

2- Senado Federal (Br). Estatuto da Criança e do Adolescente- ECA: Lei n 8069, de 13 de Julho de 1990. Brasilia (DF): Gráfica do Senado; 1991.

3-Araújo BBM, Rodrigues BMRD, Rodrigues EC. 0 diálogo entre a equipe de saúde e mães de bebês prematuros: uma análise freireana. Rev Enferm UERJ 2008, abr; 16(2): 180-86.

4. Kamada I, Rocha SMM. As expectativas de pais e profissionais de enfermagem em relação trabalho da enfermeira em UTIN. Rev Esc Enferm USP 2006; 40(3): 404-11.

5- Bowlby J. Cuidados maternos e saúde mental. $5^{a}$ ed. São Paulo (SP): Martins Fontes; 2006.

6- Zveiter M, Progianti JM. A dimensão psíquica valorizada nos cuidados imediatos ao recém-nascido. Rev Enferm UERJ. 2006 out/ dez; 14(4): 593-98. 
7- Brazelton TB. As primeiras relações. Porto Alegre (RS): Artes Médicas; 1992.

8-Carvalho MDB, Valle ERM. A pesquisa fenomenológica e a enfermagem. Acta Scientiarum 2002; 24(3): 843-47.

9- Capalbo C. Fenomenologia e ciências humanas. Londrina (PR): UEL; 1996.

10. Schutz A. El problema de la realidad social. Escritos I. Buenos Aires (AR): Amorrortu; 2003.

11. Coelho LP, Rodrigues BMRD. 0 cuidar da criança na perspectiva da bioética. Rev Enferm UERJ. 2009; 17(2); 188-93.

12- Panizza L. 0 pensamento de Alfred Schutz: sociologia fenomenológica. Rev Bras Filos 1981; 31(122): 129-41.

13- Popim RC; Boemer MR. Cuidar em oncologia na perspectiva de Alfred Schutz. Rev Latino-am Enfermagem 2005; 13(5): 677-85.

14. Gorgulho FDR, Pacheco STA. Amamentação de prematuros em uma unidade neonatal: A vivência materna. Esc Anna Nery Rev Enferm 2008;12 (1): 19-24.

15. Lam HS, Wong SP, Liu FY, Wong HL, Fok TF, Ng PC. Attitudes toward neonatal intensive care treatment of preterm infants with a high risk of developing long-term disabilities. Pediatr 2009; 123(6): 1501-508.

16. Formiga CKMR, Linhares MBM. Avaliação do desenvolvimento inicial de crianças nascidas pré-termo. Rev Esc Enferm USP 2009; 43(2): 472-80.

17- Silva RVD, Silva IA. A vivência de mães de recém nascidos prematuros no processo de lactação e amamentação. Esc Anna Nery Rev Enferm 2009; jan/mar; 13(1): 108-15. 